\title{
Damage and Performance Assessment of Protective Coatings on Turbine Blades
}

\author{
Jaroslav Pokluda ${ }^{1}$ and Marta Kianicová ${ }^{2}$ \\ ${ }^{1}$ Brno University of Technology, Brno, \\ ${ }^{2}$ Alexander Dubcek University of Trencin, Trencin, \\ ${ }^{1}$ Czech Republic \\ ${ }^{2}$ Slovak Republic
}

\section{Introduction}

Many structural components operate in very severe environments characterized by a high temperature, increasing temperature gradients, thermo-mechanical stresses and a presence of oxidizing and corrosive atmosphere. In addition, an impact of hard particles can cause failure by erosion mechanisms. Turbine blades of aircraft engines stand as a perfect example of components working in such a severe environment. They are the most loaded parts of the engine owing to the high working temperature and mechanical stresses induced by forces and moments; only centrifugal forces acting on each blade can reach several tens of $\mathrm{kN}$. Temperature patterns of incoming gases are inhomogeneous and, due to transient regimes, their temperature can increase in about $500{ }^{\circ} \mathrm{C}$ during a few seconds (Eskner, 2004). These components must withstand such a complex loading for a required performance and lifetime. They are often made from layered material systems in which interfaces between layers play a key role for a prediction of durability. Each layer has different thermal and mechanical properties. Elastic energy of the layered material is concentrated into small volumes the fracture resistance of which is lower than that of the bulk material (Bose, 2007). Therefore, quantitative approaches based on fracture mechanics can be used to assess the damage due to crack initiation and growth. Structural materials of rotor blades and their coatings determine a maximal permissible temperature of gases incoming to the high pressure turbine.

The metallic coatings on blades serve as physical barriers between the underlying substrate and the outer environment. From the point of view of corrosive and oxidizing effects, they can be divided into two categories: diffusion and overlay coatings. Diffusion aluminide coatings (DAC) are based on the intermetallic compound $\beta$-NiAl that forms under the influence of the substrate (usually Ni superalloys). On the other hand, the composition of the overlay coatings MCrAlX remains independent of the substrate alloy. In the MCrAlX alloy system, where $\mathrm{M}$ means $\mathrm{Ni}, \mathrm{Co}$, Fe (or a combination of these) and X means $\mathrm{Y}, \mathrm{Si}$, Ta, Hf, etc., the properties can be controlled and balanced for a specific application.

Thermal barrier coatings (TBCs) are composed of ceramics and represent another group of so-called multilayered coatings. These surface barriers insulate the underlying substrate from the heat flux of gases, thus contributing to an improvement of the engine performance. They consist of three constituents: (i) The thermally insulating outer layer (the TBC itself), 
typically of yttria-stabilized zirconia (YSZ); (ii) the aluminum containing bond coat (BC) located between the substrate and the TBC and (iii) the TGO which forms at the TBC/BC interface by reaction with the combustion gas. The efficiency of the thermal barrier systems depends on their heat conductivity and strain-tolerance. The heat conductivity should be very low and can be improved by alloying of the ceramics or, in columnar microstructures, by layering of the ceramic within each column (Tamarin, 2002). The strain-tolerance becomes excellent when the deposition of ceramics is performed using electron-beam physical vapor (EB-PVD). However, this technology raises the thermal conductivity of the barrier. For this reason the advanced technologies attempt to optimize both these crucial properties.

The coatings deposited on rotor turbine blades provide an optimal protect in the range of specified lifetime against destructive effects of high-temperature corrosion, oxidation and erosion provided the following requirements are satisfied (Nicholls, 2000):

- High oxidation and corrosion resistance.

- Interface stability.

- Good adhesion.

- Mechanical strength.

In addition to these requirements to metal coatings, the TBC must (Tamarin, 2002):

- $\quad$ Ensure lower average wall temperatures in cooled blades.

- To level the temperature over the blade surface and reduce thermal stresses during engine transient running.

\section{Degradation mechanisms of protective coatings}

Protective coatings used on turbine blades were developed to serve as physical barriers between aggressive environment and the substrate. In addition, TBCs are used as thermal barriers, retard creep degradation and reduce the severity of thermal gradients. Up to now, however, no coating that would fully survive the aggressive turbine environment has been found (Committee on coatings, 1996). The most serious degradation modes are as follows:

- High-temperature oxidation.

- Hot corrosion.

- Damage by thermal and thermo-mechanical fatigue.

- Mechanical damage by erosion.

- Creep degradation during overheating.

Inter-diffusion of elements at the interface with the substrate that results in a creation of undesirable phases is, sometimes, also mentioned as an independent degradation mode. Here, this mode will not be discussed in more details.

\subsection{High-temperature oxidation}

Metals and alloys exposed to oxygen or oxygen-containing gases at elevated temperatures convert some or all the metallic elements into their oxides. The oxides can create a protective phase, if they remain adherent and form thermally grown oxides (TGOs) on the top of metallic coatings by reaction with the hot gases. TGO serves as a diffusion barrier to the next oxidation and, from this point of view, the oxidation cannot be considered to be a degradation mode. The protective role of compounds such as $\mathrm{Al}_{2} \mathrm{O}_{3}, \mathrm{Cr}_{2} \mathrm{O}_{3}$ and $\mathrm{SiO}_{2}$ is to be particularly mentioned. In general, $\mathrm{Cr}_{2} \mathrm{O}_{3}$ reveals to be most protective below $871{ }^{\circ} \mathrm{C}$ while 
$\mathrm{Al}_{2} \mathrm{O}_{3}$ protects at all temperatures up to the melting point of the blade alloy (Donachie \& Donachie, 2002). In order to form adequate thicknesses of $\mathrm{Al}_{2} \mathrm{O}_{3}$ in a reasonable time, sufficiently high temperatures are required. Without the protective oxides, however, both the coating and the substrate are environmentally exposed to a rapid deterioration of their microstructure. When the oxide layer is eroded by hot gases or rubbed accidentally by removing the oxide layer, the catastrophic oxidation of the substrate can appear if the operation is continued at lower temperatures that do not allow a rapid recovery of the protective layer. A protective scale can be maintained when the aluminum, chromium or silicon do not fall below their critical levels, e.g., 4-5 of weight \% for $\mathrm{Al}$ (Committee on coatings, 1996). A rapid spallation of TGO can be also caused by internal oxidation, i.e., diffusion of oxygen into the coating. Disruption and spallation of the protective scale are exacerbated by a presence of impurities (mainly sulfur) on the metal/TGO interface. Elements as yttrium or hafnium are added to coatings to improve an adherence of aluminum or chromium scales to the substrate.

The adherent oxide scale also protects the metal surface from erosion. A general indicator of the protectiveness of the oxide scale is given by the Pilling-Bedworth Ratio (PBR), which is defined by the volume ratio oxide formed/metal consumed. The scale becomes fully protective when $\mathrm{PBR} \sim 1$. PBR $\quad<1$ means that the oxide is porous and, consequently, looses any protective properties. PBR $>1$ means that the oxide scale is highly compressed thus resulting in buckling and spallation (Bose, 2007).

Additional necessary condition to form the protective scale is a close match of coefficients of thermal expansion (CTE). Oxide scales have lower CTE than those of the underlying metals and this difference generates large stresses. Residual compressions in the TGO reach up to 3$6 \mathrm{GPa}$ as the system cools to ambient. Stresses also arise during the growth of TGO, but they are much smaller, generally less than 1 GPa (Evans et al., 2001b, Tolpygo \& Clarke, 1998). In the temperature range $(900-1000){ }^{\circ} \mathrm{C}$, only a modest oxidation of metals has been observed due to high protective properties of oxides forming on their surfaces. However, at temperatures above $\sim 1000{ }^{\circ} \mathrm{C}$, the rate of coating oxidation raises. At the same time, the diffusion processes between the coating and the substrate speed up thus resulting in a reduction of aluminum and chromium contents.

Coatings of turbine blades are oxidized during high-temperature cycles of engine running. The oxide scale growth in isothermal oxidation follows one of the following relationships (Bose, 2007):

i. Parabolic growth:

ii. Linear growth:

iii. Logarithmic growth:

$$
\begin{gathered}
x=k \sqrt{t} \\
x=x_{0}+k t \\
x=k_{0}+\log (k t+1) .
\end{gathered}
$$

Here $x$ is the oxide scale thickness after the time exposure $t, k$ is the temperature-dependent constant and $x_{0}$ and $k_{0}$ are constants. Generally, the mechanism of oxidation can be explained by a consumption of certain elements to form protective scales, while the rate of this consumption is temperature dependent. The metal coating serves as a reservoir of $\mathrm{Al}$ and $\mathrm{Cr}$ and amounts of these elements enter into life-time criteria. The aluminum reserve in a defined zone of the coating can be found from the following function (Tamarin, 2002): 


$$
m_{A l}=K \sum_{i=1}^{n} X_{i} \rho_{i} h_{i}
$$

where $m_{A l}$ is the aluminum mass fraction, $\rho_{i}$ is the density of the zone, $h_{i}$ is the zone thickness and $k$ is the alloying factor.

\subsection{Hot corrosion}

At high temperatures, the structures of engine turbines are exposed not only to oxygen but also to other constituents in the form of gas such as $\mathrm{CO}_{2}, \mathrm{SO}_{2}$, molten salts like alkali and alkaline earth sulfates, chlorides and solid particles in the form of sand and fly ashes. Solid particles can be molten by their transit through the flux of heat gases. These constituents usually originate from engine fuel impurities, contaminants of incoming air or products of imperfect combustion. Their interactions with materials cause corrosion and erosion.

Hot corrosion is a chemical reaction between the metal and molten salts in the hot oxidizing flow. The term "hot corrosion" distinguishes it from the traditional low-temperature corrosion. Salts in the form of gas have not a heavy corrosion effect but both the working process and the gas turbine environment lead to a formation of molten and solid compounds. Corrosive deposits can also seriously erode moving engine parts, including the compressor and turbine blades, thus reducing the engine efficiency. Molten salts can solidify inside cooling passages, clogging the passages and reducing or eliminating the cooling airflow, increasing blade and vane operating temperatures and shortening the engine life (NASA, 2003).

Generally, two modes of hot corrosion have been recognized (Fig. 1) (Rapp, 2001):

i. Uniform corrosion, marked as the type I or the high temperature hot corrosion (HTHC).

ii. Pit corrosion, marked as the type II or the low temperature hot corrosion (LTHC).

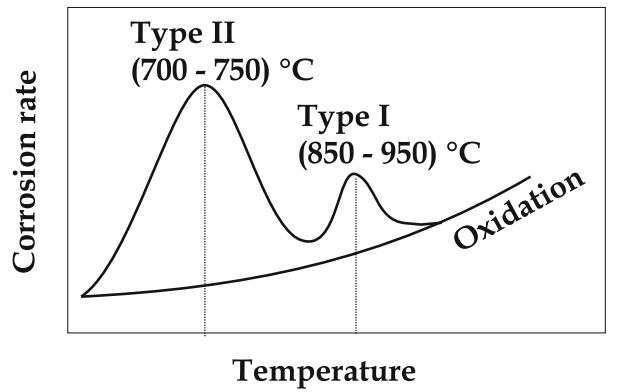

Fig. 1. Types of the hot corrosion in terms of the metal loss as a function of temperature (Bose, 2007). Copyright 2007 by Elsevier B.V., High temperature Coatings, reproduced with permission.

These forms may be affected by various conditions including the alloy composition, the thermomechanical loading, the composition of contaminants and the flux rate, the temperature cycles, the velocity and the composition of gas and erosion objects (Eliaz et al, 2002). HTHC starts with condensation of fused alkali metal salts on the surface and its microstructure consists of an outer porous oxide layer and an inner zone, depleted of $\gamma^{\prime}$ phase, that contains discrete sulphide precipitates. An intermediate zone mixed from both the oxides and the matrix can be also found between these basic layers. A very small 
amount of vanadium might be detected in these corrosion products. Elevated temperatures along with high compression and flow rates in the turbine are the main reasons for the formation of a uniform HTHC region. The high temperature has a major effect since it changes the chemical composition, fluidity and thermodynamic properties of corrosion products. High temperature gradients between the gas flux and the surface of cooled blades help the condensation of aggressive corrosion products which penetrate deeply into the coating and its substrate.

LTHC means a selective surface attack in the form of corrosion pits that form under longterm operation cycles at lower temperatures (around $700-750{ }^{\circ} \mathrm{C}$ ). The research of engine operating conditions has proved that the higher the gas-flux velocity the slower the pit corrosion damage. The analysis of the chemical composition of individual corrosion products revealed the presence of vanadium of $5-10$ weight $\%$ and a small amount of sulphur (up to 1 weight \%) (Tamarin, 2002).

Both the type I and the type II of hot corrosion retard the formation of protective oxides, thus promoting the internal oxidation and sulphidation of the substrate and its coating.

\subsection{Damage by thermal and thermo-mechanical fatigue}

Thermo-mechanical fatigue is a degradation mode which involves simultaneous occurrence of both the thermal and the mechanical strain. During repeated startups, load changes and shutdown operations, the high-temperature components of the aircraft engine experience the thermal-induced strains and stresses that cause the thermo-mechanical fatigue (TMF) damage (Huang, 2006). The coatings of blades are exposed to thermo-mechanical fatigue under cyclic changes near their ductile/brittle transition temperature (DBTT) that depends of their composition. During the thermo-mechanical fatigue, different failure mechanisms operate below and above the DBTT. It was found that fine-grained MCrAlX coatings undergo a typical transition in their mechanical behavior as a function of temperature. They exhibit a ductile behavior and low strength at high temperatures while a brittle behavior and high strength is observed below the DBTT (Bose, 2007).

\subsubsection{The stresses in the TGO}

The stresses in the TGO exert a central effect on a failure of the TBC multilayered thermal protection system. There are two main sources of these stresses: one from the thermal expansion misfit upon cooling and the other one from the TGO growth (Evans, 2001b). Both stresses can be alleviated by the TGO creep and redistributed in the vicinity of imperfections; they can be also modified by thermal cycling that causes a cyclic plasticity of BC. Because of a low thermal expansion coefficient of TGO, a large in-plane compressive stresses can develop upon cooling. At ambient, when the TGO remains planar without rumpling, the compressive stresses are in the range $\sigma_{T G O} \in(-3,5 ;-6) G P a$, depending on the thermal expansion misfit (Evans, 2008).

In the case when rumpling of TGO occurs, the compressive stresses are reduced. During the growth under influence of lateral compressive stresses, the thin TGO layer $(3-10 \mu \mathrm{m})$ seeks mechanisms to relieve the compression by means of out-of-plane displacements. Both the magnitude and the sign of these displacements are governed by mechanical properties of $\mathrm{BC}$ and TBC. The BC at high temperatures is relatively soft and, consequently, the displacements proceed predominately into the BC, as evident in Fig. 2. (Tolpygo et al., 2004). This process is marked as "roughening" or "ratcheting" and may lead to local separations at 
the interface TBC/TGO. Imperfections of the TGO and redistribution of stresses at the interface are evident in the schematic picture, where the tensile stresses $\sigma_{\mathrm{zz}}$ develop at the concave site of TGO while the compressive stresses $\sigma_{z z}$ appear at the convex site. Shear stresses $\sigma_{x^{\prime} z^{\prime}}$ are induced at inclined sections (see Fig. 3.). The magnitude and the sign of stresses depend on both the elastic modulus mismatch and the ratio of the amplitude $A$ to the wavelength $L$.

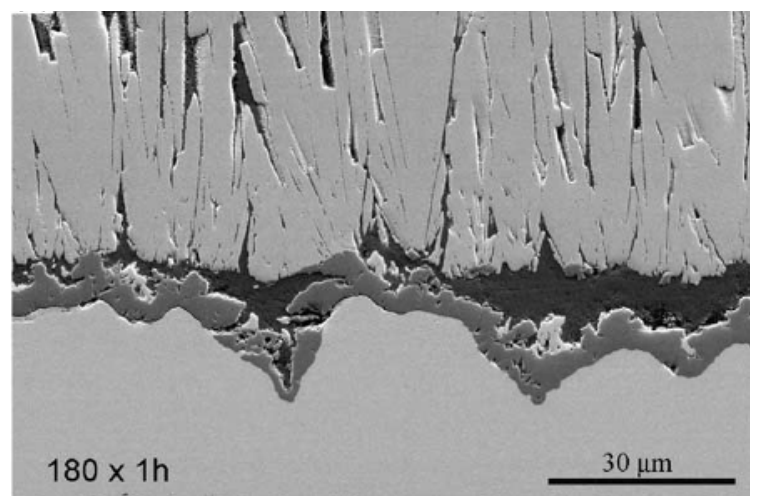

Fig. 2. The microstructure of TBC/TGO interface separation after thermal cycling at $1150{ }^{\circ} \mathrm{C}$ (Tolpygo, Clarke \& Murphy, 2004). Copyright 2004 by Elsevier B.V., Surface and Coating Technology. Vol. 188-189, reproduced with permission.

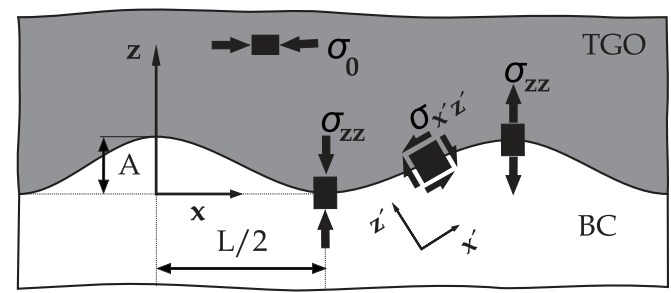

Fig. 3. The scheme of the stress redistribution on the interface.

When the TGO is thin relative to both the amplitude A and the wavelength $L$, i.e. $h / L<<1$, the stresses can be expressed as

$$
\frac{\sigma_{i j}}{\sigma_{0}}=H_{i j}\left(\alpha_{D}, \frac{h}{L}\right) \frac{A}{L}
$$

where $\sigma_{i j}$ are the stress-tensor components $(i, j=1,2,3), \sigma_{0}$ is the compressive stress in the oxide

$$
\sigma_{0}=\frac{E_{1} \Delta \alpha \Delta T}{1-v_{1}}
$$

$\Delta a$ is the difference in thermal expansion coefficient between the TGO and BC and $\Delta T$ is the amplitude of the temperature change (He et al., 1998). The function $H_{i, j}$ depends on the Dundurs'parameter 


$$
\alpha_{D}=\frac{\bar{E}_{1}-\bar{E}_{2}}{\overline{\bar{E}}_{1}+\bar{E}_{2}},
$$

where $\bar{E}_{i} \equiv \frac{E_{i}}{1-v_{i}^{2}}$ is the plane-strain Young's modulus of elasticity $\left(\bar{E}_{i} \equiv E_{i}\right.$ in plane stress) and subscripts 1 and 2 refer to the materials creating interface. The thicker is the TGO (the larger the ratio $h / L$ ), the higher the values of stress components (Hutchinson \& Suo, 1992). The redistribution of the normal (shear) stresses $\sigma_{z z}\left(\sigma_{x^{\prime} z^{\prime}}\right)$ for particular ratios $h / L=1$ and $A / h$ $=0.1,0.2,0.3$ and 0.5 is plotted in the Fig. 4 . (Evans, 2001a).

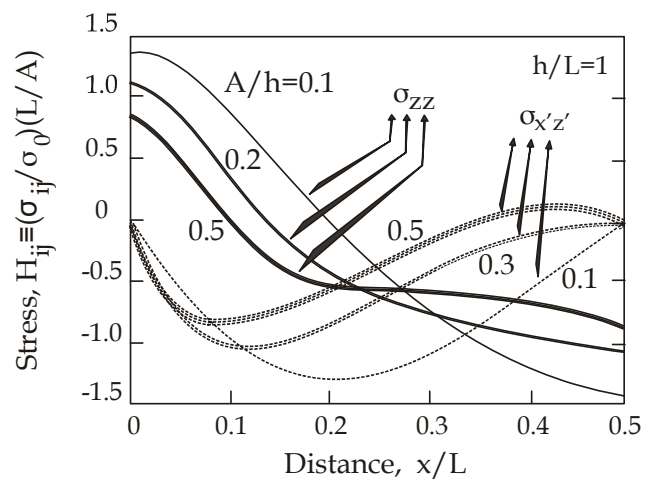

Fig. 4. Distribution of stresses on the BC/TGO interface (Evans,2001a). Copyright 2001 by Elsevier B.V., Progress in Materials Science. Vol. 46, reproduced with permission

\subsubsection{Main design approaches to failure of thin layers}

Nowadays, two different design approaches to bulk structures are basically applied. The stress approach is based on the measurement of strength characteristic $S$ of the bulk material and calculation of the stress field in a real structure. If the maximum stress is lower than the material strength, i.e. $\sigma_{\max }<S$, the structure is considered to be safe. The energy approach is based on the Griffith stability condition which means that the fracture toughness $\Gamma$ of a cracked solid must be higher than the energy release rate $G$, i.e., $G<\Gamma$ (Suo, 1993). Thus, for a pre-existing crack of a length $2 a$ in infinite elastic solid subjected to a tensile stress $\sigma$, the following condition of crack stability must be fulfilled:

$$
\frac{\pi \sigma^{2} a}{E}<\Gamma
$$

In the case of real structures with finite dimensions, the energy approach demands information about a pre-existing crack configuration, i.e., its location, geometry, size and orientation in the structure. However, such information is practically impossible to be obtained for real structures as integrated circuits or structures protected by various types of thin coatings. Therefore, the main effort was devoted to numerical solutions for typical crack configurations in the substrate-coating systems.

Components of the turbine engines are protected from the aggressive environment by thin coatings. In these layered materials, the interfaces are the most critical parts because of their 


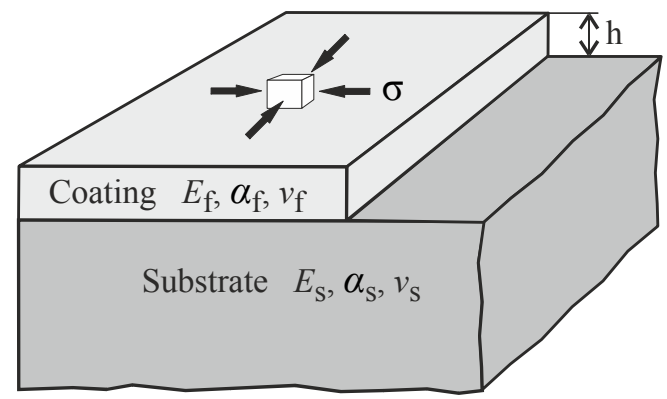

Fig. 5. Scheme of the system substrate/coating

heterogeneity, different thermal and elastic characteristics and presence of residual stresses. Failure of these systems can be, in principle, predicted using elastic fracture mechanics. The relatively simplest analysis can be done in the case of a very thick substrate and thin coatings in which an extent of plastic processes can be neglected. Let us consider a thin film $h$ on a thick substrate according to the scheme in Fig. 5. Both the substrate and the film are assumed to be isotropic and linearly elastic, with elastic moduli, thermal expansion coefficients and fracture toughness $\left(E_{\mathrm{s}}, v_{\mathrm{s}}, a_{\mathrm{s}}, \Gamma_{\mathrm{s}}\right)$ and $\left(E_{\mathrm{f}}, v_{\mathrm{f}}, a_{\mathrm{f}}, \Gamma_{f}\right)$, respectively. In general, the material constant $\Gamma$ represents energy necessary for creating a crack of a unit area in the layer, substrate or at their interface. The difference in elastic moduli is characterized by Dundur's parameters $a_{D}$ and $\beta_{D}$. The parameter $a_{D}$, as defined by eq. (7), is a measure of incompatibility between the Young's moduli whereas the parameter $\beta_{D}$ measures the difference in bulk moduli. The layer is stiffer (softer) than the substrate when $a_{D}>0\left(a_{D}<0\right)$. While the opening mode I is usually assumed to be a proper loading mode for the crack growing in the substrate or the layer, the mixed mode I+II must be considered for the crack propagating along (or towards) an interface. The latter case is rather complicated and, therefore, we will start with the stability assessment for a crack configuration within a thin layer. Here the energy released rate reads

$$
G=\frac{\Omega h \sigma_{0}^{2}}{E_{f}}\left(1-v_{f}\right),
$$

where $\Omega \in(0.3,4.0)$ is the dimensionless factor depending on both elastic moduli and geometrical parameters of the crack configuration and $E_{f}$ is the Young modulus of the layer (Hutchinson \& Suo, 1992). The strain induced by cooling from a high temperature $T_{0}$ to the ambient temperature $T_{T}$ due to a contraction difference can be expressed as

$$
\sigma_{0}=\frac{E_{f}}{1-v_{f}} \varepsilon_{T}=\frac{E_{f}}{1-v_{f}}\left(\alpha_{f}-\alpha_{s}\right)\left(T_{0}-T_{T}\right) .
$$

When combining eqs. (8a) and (9) along with the condition $G<\Gamma$ one obtains

$$
\Gamma_{f}>\Omega h \varepsilon_{T}^{2} \bar{E}_{f} .
$$

The general relation (10) shows that the crack stability can be improved by reducing strain or residual stresses in the coating, lowering the coating thickness, raising the fracture 
toughness $\Gamma_{\mathrm{f}}$ and utilizing more compliant materials. Consequently, the critical coating thickness still ensuring the crack stability is determined as follows:

$$
h_{c}=\frac{\Gamma_{f}}{\Omega \varepsilon_{T}^{2} \bar{E}_{f}} .
$$

\subsubsection{Failure modes of TGO}

Cracking initiates predominantly within the TGO/substrate interface and proceeds by a small-scale buckling of the TGO layer (Wang \& Evans, 1999).

This process consists of the following stages:

i. Partial separation of TGO from the substrate that initiates at interface inhomogeneities;

ii. Buckling of the separated TGO segment and further growing of the related interface crack;

iii. Spalling of the TGO segment.

\section{Partial separation of the TGO segment from the substrate}

This failure mode can be caused by the following processes:

- Void coalescence on the interface as a result of non-equilibrium diffusion fluxes of metallic ions during the through-boundary oxidation. Unbalanced diffusion fluxes create a high concentration of vacancies that produce microvoids.

- Creep and grain-boundary sliding in the substrate leading to decohesion of the oxide film from the substrate.

- $\quad$ Rippling of the TGO/substrate interface induces tensile stresses that, assisted by voids and inclusions, separate the oxide layer from the substrate.

- Thickness variations during an imperfect growth of TGO, e.g., due to formation of volume-inconsistent $\mathrm{Y}_{2} \mathrm{O}_{3}$ phases.

A minimal thickness of the TGO layer $h_{\mathrm{f} \text {,min }}$ below which no separation occurs is defined by eq. (11), where $\Omega \approx 1$ and $\Gamma_{f} \rightarrow \Gamma_{i}^{O}, \Gamma_{i}^{O}$ is the fracture toughness of the interface for the opening loading mode. On the other hand, the critical thickness for TGO failure $h_{\mathrm{f}, \mathrm{c}}$ can be, in most cases, expressed as

$$
h_{f, c}=\xi h_{f, \min },
$$

where $\xi>1$. Lower values of $\Gamma_{i}^{O}\left(\approx 5 \mathrm{~J} \cdot \mathrm{m}^{-2}\right)$ are usually associated with a segregation of impurities (mostly sulphur) on the TGO/substrate interface. A very tough TGO/substrate interface of $\Gamma_{i}^{O} \approx 20 \mathrm{~J} \cdot \mathrm{m}^{-2}$ manifests itself by internal cracking of TGO. When using typical values $E_{f}=(350-400) M P a, \sigma_{0}=(3-4) G P a$ and $\Gamma_{i}^{O}=5 J . m^{-2}$, one obtains $h_{f, \min } \in(0.1 ; 0.4)$ $\mu \mathrm{m}$. Thickness values of this range are an order of magnitude smaller than those of real TGO separates (Hutchinson \& Suo, 1992).

\section{Buckling of the TGO layer}

When a symmetric circular separate, subjected to a particular stress, reaches a critical radius $b_{b}$ it expands to create a buckle. According to (Wang \& Evans, 1999), the critical value of the biaxial compressive stress $\sigma_{\mathrm{b}, \mathrm{c}}$ for buckling of the circular TGO separate can be expressed as 


$$
\sigma_{b, c}=\Pi_{c} \frac{E_{f}}{1-v_{f}^{2}}\left(\frac{h_{f}}{b_{b}}\right)^{2},
$$

where $h_{f}$ is the TGO thickness and $\Pi_{c}=1,22$ is the so-called critical index of buckling. When assuming only dilatation-induced compressive stress on the TGO/substrate interface $\sigma_{0} \approx 3,5 \mathrm{GPa}\left(h_{f}=5 \mu \mathrm{m}\right)$, the critical buckling radius $b_{b, c} \approx 50 \mu \mathrm{m}$.This value is much higher than the real one, which is caused by tensile stresses that are induced on the real rippled interfaces. The buckled separate starts to extend when the energy release rate $G$ exceeds the interface fracture toughness $\Gamma_{i}$, i.e., $G \geq \Gamma_{i}$.

Since the buckle can extend under general mixed mode I+II, the value of $\Gamma_{i}$ depends on a particular crack-tip loading mode:

$$
\begin{gathered}
\Gamma_{i}(\psi)=\Gamma_{i}^{O} f(\psi), \\
f(\psi)=1+\operatorname{tg}^{2}[(1-\lambda) \psi], \\
\psi=\operatorname{tg}^{-1} \frac{K_{I I}}{K_{I}}
\end{gathered}
$$

where $\psi$ is the loading phase angle, $K_{I}$ and $K_{I I}$ are the stress intensity factors in modes I and II and $\lambda$ is the coefficient depending of the interface roughness $(\lambda=1$ corresponds to a smooth surface, $\lambda=0$ to a rough surface). The plot of the function $f(\psi)$ can be found in (Hutchinson \& Suo, 1992).

\section{Spallation of the TGO layer}

Deflection (kinking) of the crack from the interface towards the TGO interior appears in consistence with a criterion taking both the loading mode and the ratio $\Gamma_{i}^{O} / \Gamma_{f}$ into account (Hutchinson \& Suo, 1992). If the fracture toughness of the interface is sufficiently high, i.e. $\Gamma_{i}^{O} / \Gamma_{f}>0.6$, the kinking appears before the onset of crack extension (Wang \& Evans, 1998), which means that $b_{s, c}=b_{b, c}$, where $b_{s, c}$ is the critical radius of spallation (Fig. 6a.). The critical stress for the spallation of the buckled TGO segment is given by the relation

$$
\sigma_{s, c}=\varphi^{*} \sqrt{\frac{E_{f} \Gamma_{i}^{O}}{\left(1-v_{f}\right) h_{f}}},
$$

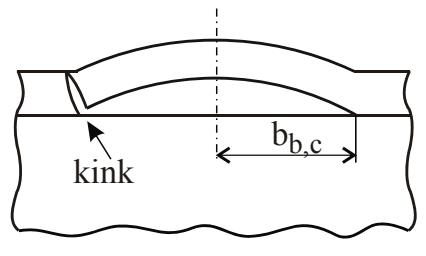

a)

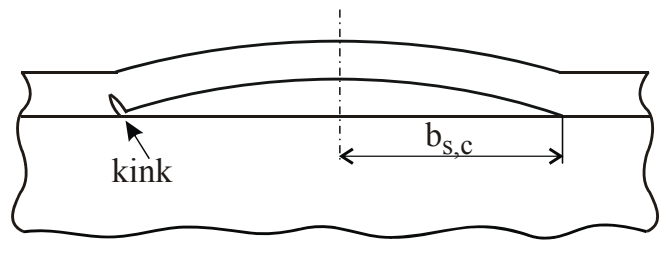

b)

Fig. 6. Kinked cracks at the radii: a) $b_{b, c}$ and b) $b_{s, c}$. 
where $\varphi^{*} \approx 1,7$ (He et al., 1998). In the case of lower values $\Gamma_{i}^{O} / \Gamma_{f}$, the buckle is extended along the interface before its spallation by reaching the critical radius $b_{s, c}$ (Fig. 6b.).

According to (Hutchinson \& Suo, 1992), the ratio of the critical length $b_{s, c}$ and the thickness $h_{f}$ can be expressed as

$$
\frac{b_{s, c}}{h_{f}}=\chi \sqrt{\frac{E_{f}}{\sigma_{o}}},
$$

where

$$
\chi \approx 1,1 \exp \left[0,7 \frac{\Gamma_{f}}{\Gamma_{i}^{O}}-1,25\right] .
$$

Thus, the critical parameters that control both the extension and the spallation of the TGO separate are $\sigma_{\mathrm{o}}, h_{f}, \Gamma_{i}^{O}$ and $\Gamma_{f}$. Initiation and extension of this degradation mode operating on the BC/TGO interface can be assessed by using so-called spallation maps that identify regions of individual damage stages (Wang \& Evans, 1999).

\subsubsection{Failure modes of TBC}

\section{Mechanism of TBC degradation assisted by heterogeneities}

The presence of the thermal barrier suppresses the small buckles. Therefore, the damage proceeds by creating a large scale buckling (LSB) that develops on the interface after reaching a critical size. During the thermal exposure, the TGO/BC interface embrittles due to segregation of impurities (mainly $S$ ) that reduce its adhesion strength and fracture toughness $\Gamma_{i}^{O}$ (Evans et al., 1999). This stimulates extension of separates in the vicinity of coarsed and/or rippled TGO segments. The TGO imperfections are crucial for the life span of TBC systems also because of tensile hoop stresses $\sigma_{z z}$, perpendicular to the YSZ/TGO interface that are induced in their proximity and initiate radial cracks within the TBC layer. At high temperatures, these cracks do not penetrate the TGO since the ductility of this layer causes a redistribution of stresses at their inner front. Moreover, the TGO/bond-coat interface is in compression, thus prohibiting its separation. Consequently, the cracks remain confined to the TBC during exposure. When cooling to ambient, however, the thermal expansion misfit induces tensile stresses normal to the TGO/BC interface thus inducing its separation. A mutual coalescence of interface and radial cracks is a key event of the TBC degradation (Fig. 7b.) which is surmised to happen upon cycling in the range of intermediate temperatures. In this range, the TGO layer remains brittle and the hoop tensions are not replaced by compression related to the thermal expansion misfit. Since the cracks emanating from individual imperfections are too small to satisfy large-scale buckling conditions, many such cracks must coalesce (Rabiei \& Evans, 2000).

Creation of continuous cracking demands a development of a critical TGO thickness as

$$
h_{c}=\frac{2 \sqrt{\pi}\left(1-v^{2}\right) m d^{\frac{3}{2}} K_{T c}^{Y S Z}}{(m-1) R E_{Y S Z}},
$$




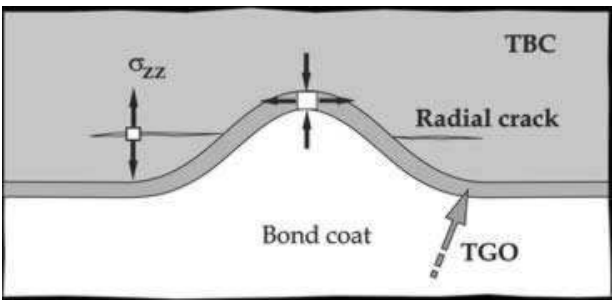

a)

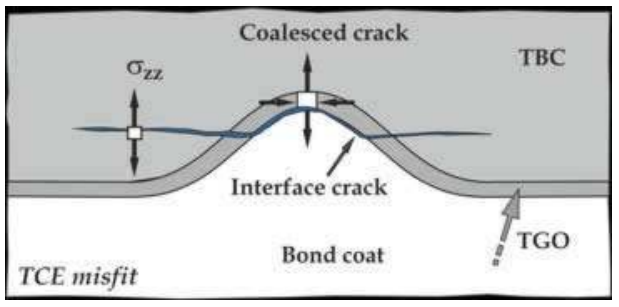

b)

Fig. 7. a) Radial cracks induced in the TBC; b) Coalescence of radial cracks with the interface separation caused by TGO growth and followed by cooling to ambient (Evans et al., 1999). Copyright 2000 by Elsevier B.V., Acta Materialia. Vol. 48, reproduced with permission where $m$ is the volume ratio of newly created TGO to exhausted BC ( $m=1$ for no volume changes), $d$ is the half-spacing of two adjacent heterogeneities, $K_{T c}^{Y S Z}$ is the fracture toughness of YSZ for short cracks $(a \leq 100 \mu \mathrm{m})$ under mode I and $R$ is the radius of a circular heterogeneity (Evans et al., 2001b).

Thus, both the high $R$ and the small $d$ of ripples at the TGO/bond-coat interface increase the probability of continuous cracking inside the thermal-barrier coatings. These ripples are formed by the ratcheting process under thermal cycling that relaxes compressive residual stresses within coatings (He et al., 2000). When the TGO becomes rippled, the shear stresses in the substrate can exceed yield stress and, consequently, the amplitude of the rippling raises by plastic deformations of the substrate. The related tensile strains $\mathcal{E}_{z z}$ and stresses $\sigma_{\mathrm{zz}}$ in the YSZ layer nucleate cracks parallel to the interface according to the scheme in Fig. 7., as documented in Fig. 8. This cracking leads to the spallation (as already mentioned for LSB) or to the edge cracking. In the case of planar TGO, on the other hand, the absence of shear stresses in the substrate (except for free edges) means that there are no out-of-plane displacements as reactions on the thermal cycling (Evans et al., 2003).

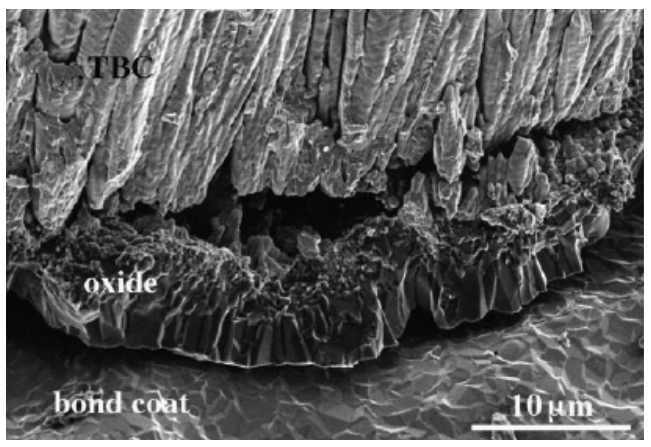

Fig. 8. Cracking of TBC due to cyclic plastic deformation and decohesion of the TBC/TGO interface (Tolpygo \& Clarke, 2000). Copyright 2000 by Elsevier B.V., Acta Materialia. Vol. 48, reproduced with permission

\section{Degradation of TBC by penetration of sulphide sediments and air sands}

YSZ layers utilized for burning parts of aircraft engines are subjected to temperature gradients developing in the course of service. Recent investigations and monitoring of real 
components from the burning parts of turbines reveal that the YSZ coatings are susceptible to damage in sites of a dense microstructure (Borom et al, 1996). With regard to the environment in the turbines, such dense layers can be formed not only by penetration of calcium-magnesium-alumino-silicate (CMAS) particles $\left(\mathrm{CaO}, \mathrm{MgO}, \mathrm{SiO}_{2}, \mathrm{Al}_{2} \mathrm{O}_{3}\right)$ and/or sulfides but also by sintering of the layer fringe.

The sand CMAS particles damage the turbine blades particularly in aircrafts flying at lower altitudes over arenaceous regions. The damage by sulfides is typical for components exposed to a seaside atmosphere. These very small particles (smaller than $10 \mu \mathrm{m}$ ) do not posses a sufficient kinetic energy to cause the impact damage (Strangman et al., 2007). When the temperature of the TBC surface exceeds the melting temperature $T_{m C M A S} \approx 1240{ }^{\circ} \mathrm{C}$ of CMAS compounds, the CMAS layer starts to melt, bedraggle the YSZ and, by action of capillary forces, it draws in the spaces of columnar oxides to a depth where $T_{T B C}=T_{m C M A S}$. After cooling, the CMAS layer hardens and forms a fully dense phase which thermomechanical properties increase its tendency to spalling (Mercer et al., 2005). The YSZ volume containing the penetrated coat has a higher elasticity modulus and, at the same time, a release of yttrium from the YSZ can cause its transformation from the tetragonal to the monoclinic structure (Borom et al., 1996). Regions penetrated by CMAS phase are also detrimental due to a reduction of thermal conductivity of the TBC barrier.

Damage of the coating can be particularly identified inside three zones (Krämer et al., 2008):

- Zone I - superficial penetration of CMAS; the densified region contains a number of dense vertically cracked (DVC) system, the spacing of which is about $0.2 \mathrm{~mm}$. Because of a very thin CMAS layer on the surface, however, the total volume remains identical with the original one.

- Zone II - intermediate penetration of CMAS: damage is similar to that in the zone I but the surface is smoother.

- $\quad$ Zone III - depth penetration of CMAS: an extended infiltration of CMAS results in a network of long vertical cracks close to the bond coat (see Fig. 9.).

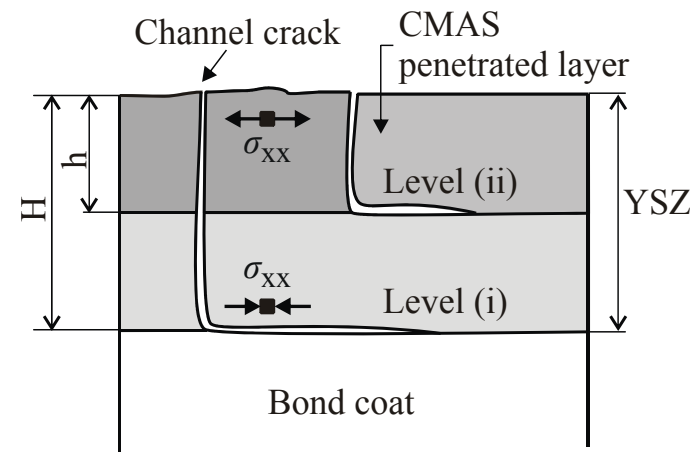

Fig. 9. Scheme of cracks at levels (i) and (ii) inside the zone III.

When the ratio of the penetration depth $h$ to the total thickness $H$ of the YSZ layer reaches $h / H \approx 0.5$, the cooling from high temperatures induces surface tensile stresses that drive the cracked channels to grow throughout the TBC layer. Further cooling results in accumulation of elastic energy at the level (ii) that is high enough to form and propagate mode I cracks in the direction parallel to the surface. Later on, the elastic energy accumulated in the zone III, 
level (i), becomes sufficient to drive the cracks from deep channels in mixed mode over the bond coat. This means that there must be a critical penetration depth $H_{\text {pen }}^{*}$ below which no cracking of TBC coating appears (Krämer et al., 2008). This critical depth can be expressed as

$$
H_{\text {pen }}^{*}=\frac{3,6 k}{\kappa \Lambda^{\frac{2}{3}}},
$$

where $k$ is the coefficient of thermal conductivity of the penetrated layer, $k$ is the coefficient of heat transfer on the TBC surface and $\Lambda \approx 800$ is the material constant (Mercer et al., 2005).

\subsection{Mechanical damage by erosion}

Mechanical damage of coatings may also be initiated by intrusion of foreign particles into the gas-air space of turbines at high operating temperatures that facilitate plastic deformations of thermal barriers. Working conditions and the turbine environment can speed the oxide particles, sized $10-1000 \mu \mathrm{m}$, to velocities as high as $200 \mathrm{~m} . \mathrm{s}^{-1}$ (Crowel et al., 2008). In gas turbines, such a high velocity can also be reached with a help of the rotation motion of the runner. Thus, these particles cause additional mechanical damage by impact and erosion. Spallation of the coating due to both the TGO growth on the BC/TBC interface and the thermal mismatch stresses was, for a long time, the main damage process of thermal barrier coatings. Starting with the application of EB-PVD depositions, erosion and impact of hard particles became the most important damage processes in the case of TBC with a columnar structure.

\subsubsection{Impact of small particle with low kinetic energy}

Impact of small particles on the surface of TBCs with columnar structure initiates short cracks that do not further propagate through the coating since the column boundaries act as growth inhibitors (Wellman et al., 2005). Particularly in the case of a low kinetic energy and temperature, the formation of dense plastic surface layer is impossible and the columns remain separated. Such an elastic impact induces zones of local tensile stresses in the surface region close to the impact site. These stresses cause local bending of columns and initiate knocking off the column edges. Because such impact processes are of a very short-term character $(\sim 10 \mathrm{~ns})$, the stresses are controlled by elastic waves. A schematic picture of this mechanism is shown in Fig. 10. (Chen et al., 2004).

\subsubsection{Impact of medium-sized particle with mediate kinetic energy}

Such impacts usually create the so-called densified zone (DZ) which, however, is too thin to cause damage high enough to delaminate the TBC/TGO interface. Subsequent impacts of particles form a thin DZ until tensile-stress concentrations induce a partial decohesion at the DZ/column interface. These stresses are, again, induced by elastic waves. Further impacts rebuild the DZ during the time span of $1 \mathrm{~ms}$. Mechanism of such a damage is schematically depicted in Fig. 11. (Chen et al., 2004).

\subsubsection{Impact of large particle with high kinetic energy}

When a large particle impacts on the surface at a high temperature, the major part of its kinetic energy is absorbed by plastic deformation and creation of DZ in a close proximity of 


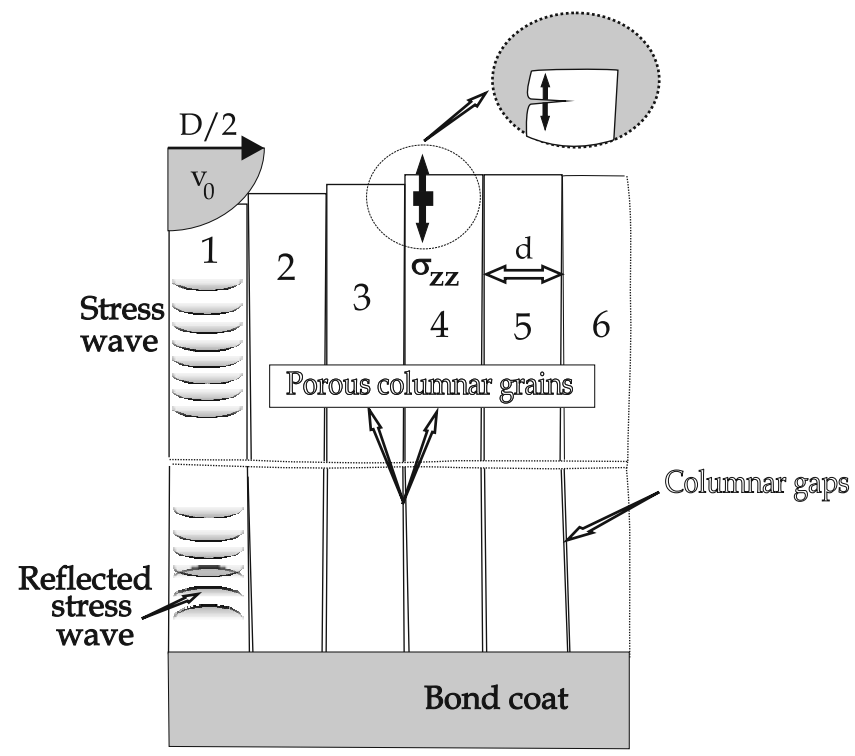

Fig. 10. Scheme of damage processes associated with an impact of a small particle (Chen at al., 2004). Copyright 2004 by Elsevier B.V., Wear. Vol. 256, reproduced with permission

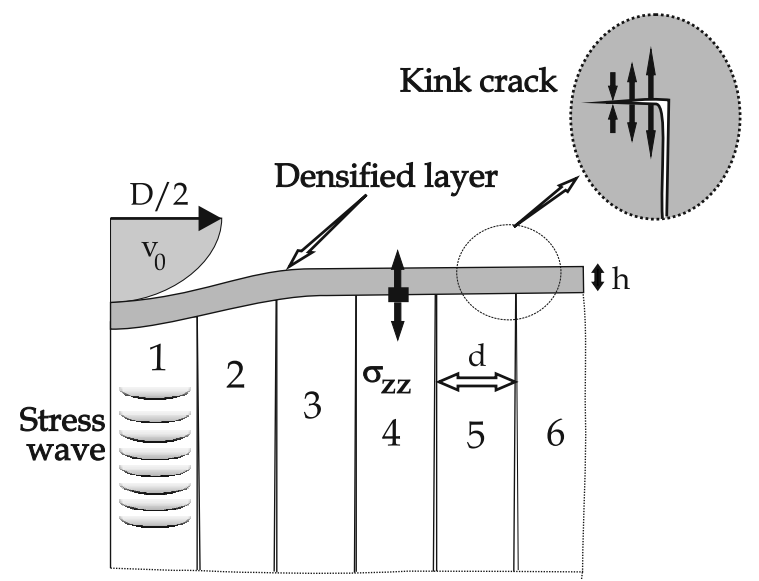

Fig. 11. Scheme of damage processes associated with an impact of a medium-sized particle (Chen et al., 2004). Copyright 2004 by Elsevier B.V., Wear. Vol. 256, reproduced with permission the impact site. The particular damage mechanism depends on the size and velocity of particles, temperature and material (Nicholls et al., 1998). Plastic deformation within DZ might be accompanied by bands of columns that are inclined at nearly $45^{\circ}$ from the surface and contain cracks. The width of these bands is several times higher than that of the individual column (Crowell et al., 2008). When the band reaches the TBC/TGO interface, the cracks grow along this boundary, i.e., parallel to the surface. A scheme of related damage mechanisms is shown in Fig. 12. (Chen et al., 2003). 


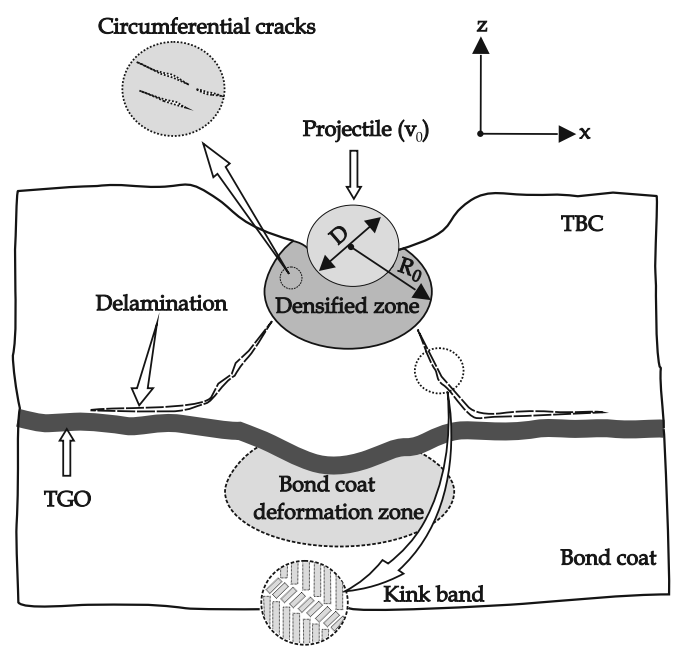

Fig. 12. Scheme of damage processes associated with an impact of a large particle (Chen et al., 2003). Copyright 2002 by Elsevier B.V., Materials Science and Engineering. Vol. 352, reproduced with permission

\subsection{Creep degradation after overheating}

Overheating means an exposure of a material to an excessive temperature during a short time. The excessive temperature is, however, a relative term since, for some unloaded components, it need not necessarily cause serious problems. Indeed, this could only lead to a partial reduction of materials strength and/or ductility.

In general, any temperature should be considered as the overheating one when it has the following consequences (Donachie \& Donachie, 2002):

i. melting down particularly the grain-boundary phases;

ii. dissolving of strengthening phases in the matrix;

iii. extraordinary oxidation and corrosion.

These effects are dependent of both the temperature level and the time span. The melting of selected phases cannot be recovered by any heat treatment. Relevant melting temperatures are displayed in tab. 1 for several Ni-based cast alloys (Donachie \& Donachie, 2002).

\begin{tabular}{lcc}
\hline \multicolumn{1}{c}{ Alloy } & Melting temperature $\left({ }^{\circ} \mathrm{C}\right)$ & Solidus $\gamma^{\prime}\left({ }^{\circ} \mathrm{C}\right)$ \\
\hline & $1225-1230$ & 1150 \\
Rene 80 & $1175-1200$ & 1180 \\
IN 100 & 1260 & $1180-1200$ \\
MAR-M-200 & 1260 & 1150 \\
B-1900 & $1315-1330$ & - \\
PWA 1480 & 1315 & - \\
CMSX-3 & 130 \\
\hline
\end{tabular}

Table 1. Melting temperatures of cast Ni-alloys and strengthening $\gamma^{\prime}$ phase 
Example of dissolving of grain-boundary phases after overheating associated by a reduction of creep strength is given in Fig. 13. (Donachie \& Donachie, 2002).

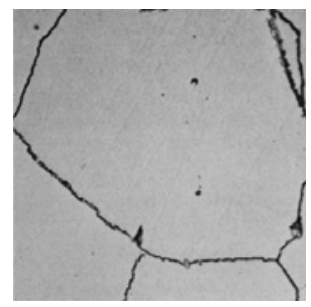

(a)

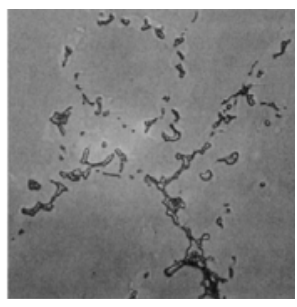

(b)

Fig. 13. Microstructure of a nickel-alloy: (a) before overheating; (b) after overheating (Donachie \& Donachie, 2002, 2004). Copyright 2002 by ASM International, Superalloys: a Technical Guide, reproduced with permission

In practice, the high-temperature components as stator and rotor blades of aircraft turbines are damaged by overheating due to the following events:

i. Escalation of the working temperature by surging, wrong composition of the combustion fuel, burning outside the combustion chamber and human factors (Pokluda et al., 2008).

ii. Damage of air-cooled blade channels by creep deformation (Tawancy \& Al-Hadrami, 2009).

iii. Intrusion of foreign particles into the engine.

iv. Insufficient filtration of the inlet a blocking of cooling channels by various contaminants (volcanic ash, sands) that subsequently melt in the channels (Report NASA, 2003).

If the critical temperature of gases becomes higher than nominal, damage of hot section components starts to be very extensive during a very short time and it is accompanied by plastic deformation and cracking particularly on the surface. A lot of papers deal with an effect of creep mechanisms on the degradation of superalloys with protective coatings (Tawancy \& Al-Hadrami, 2009, Ciesla \& Swadzba, 2006). The latter paper, for example, reports on the evaluation of damage of aluminium layers on the nickel base superalloy after short time creep tests. Analyses of specimens revealed numerous voids and microcracks at the grain boundaries of the substrate. During overheating and further thermal cycling in service, such defects can develop to cracking along and through the thickness of coatings (Tawancy \& Al-Hadrami, 2008, Evans et al., 2003, Rangaraj \& Kokini, 2003). Because the thermal expansion coefficient of the coating $a_{c}$ is lower than that of the substrate $a_{s}$, the coating experiences compressive stresses after cooling down from the deposition temperature (Wang et al., 2005). When the service temperature is reached, the compressive stresses become substantially reduced also by the substrate/coating relaxation. During the first part of the overheating stage, however, the compressive stress again appears as a consequence of the coating/substrate temperature gradient (Rangaraj \& Kokini, 2003). This is schematically shown in Fig. 14. (Pokluda \& Kianicova, 2010). However, both the high heat conductivity and the low thickness of the diffusion layer eliminate the temperature gradient very quickly and, when the peak overheating temperature is nearly reached, the stress changes to a tensile one. In general, the delay between the onset of the overheating and that of the tensile stress (the range $t_{1}-t_{0}$ ) depends on the layer thickness and the heat conductivity of both the diffusion layer and the substrate. The tensile stress induced in the 
coating steeply increases during the first stage of the cooling period and, for a certain period of time $t_{3}-t_{2}$, retains its sign also after the termination of the overheating period (Fig. 14.). During a further service, both the sign and the level of relatively low stresses in the coating are determined by thermal cycling around the service temperature (flight manoeuvres) and depend on the stress-strain response of both the coating and the substrate, i.e., on their mechanical hysteresis and tendency to ratcheting (Wang et al., 2005).

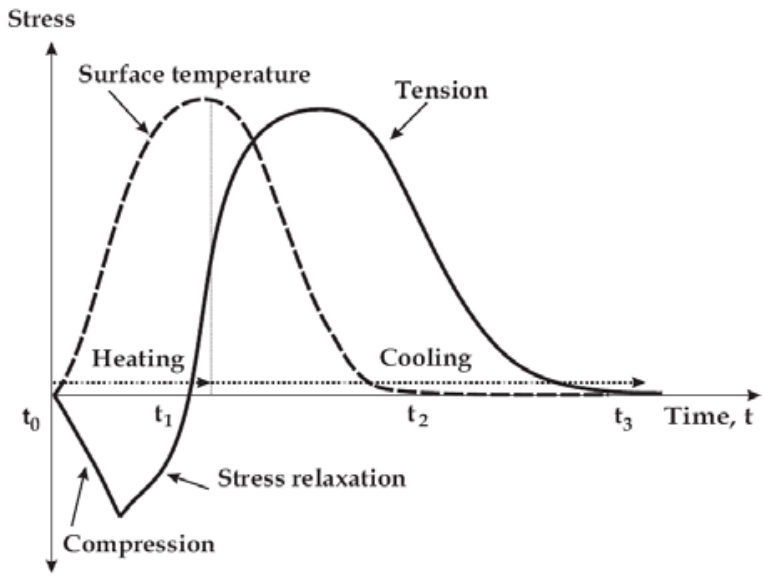

Fig. 14. Scheme of the development of thermal stresses in the coating layer during the overheating process (Pokluda \& Kianicova, 2010). The heating curve and the related timedependence of the thermal stresses are respectively plotted by the dashed and the full line. Copyright 2010 by Elsevier B.V., Engineering Failure Analysis (in print), reproduced with permission

\section{Case study: assessment of performance capability of Al-Si coatings after overheating}

Motivation for this study came from a demand for a substantial extension of our knowledge about microstructural degradation of diffusion Al-Si coatings (AS layers) protecting rotor blades of the aircraft engine DV2 produced by HTC-AED a.s., Považská Bystrica, Slovakia. The engine is appointed for light training combat aircrafts, where sudden changes of the engine output are in progress during flight maneuvers. Rotor blades of the high-pressure turbine are the most heavily loaded components of the runner wheel. They experience a variety of loading during starts-up and shuts-down and undergo sudden changes of loading during flight manoeuvres. Owing to surging, an overheating shock can appear so that the working temperature $T$ of blowing gases exceeds its critical value $T_{c}=760^{\circ} \mathrm{C}$ (Kianicová, 2006). The producer has to decide about their further performance till the next general repair on the basis of an extract of preceding overheating data. For that purpose, an empirical degradation parameter is used as

$$
D=\left(t_{2}-t_{0}\right)\left(T_{\max }-T_{c}\right)^{3} \int_{t_{0}}^{t_{2}}\left[T(t)-T_{c}\right] d t,
$$


where $t \in<t_{0}, t_{2}>$ is the overheating duration, $T>T_{c}$ and $T_{\max }$ is the maximal overheating temperature (HTC-AED, 1998). By means of that procedure and Tab. 2, the producer meets a statement concerning the performance capability.

\begin{tabular}{|c|c|c|}
\hline$D\left[{ }^{\circ} \mathrm{C}^{4} \cdot \mathrm{s}^{2}\right]$ & Engine status & Performance capability \\
\hline $10^{5}<D \leq 1.5 \times 10^{9}$ & Full performance capability (FPC) & Operation \\
\hline $1.5 \times 10^{9}<D \leq 10^{10}$ & $\begin{array}{l}\text { Degraded layer on rotor blades } \\
\text { of the high-pressure turbine (DHB) }\end{array}$ & Repair \\
\hline $10^{10}<D \leq 10^{12}$ & $\begin{array}{l}\text { Degraded basic material of rotor blades } \\
\text { of the high-pressure turbine (DBM) }\end{array}$ & Repair \\
\hline $10^{12}<D \leq 10^{14}$ & $\begin{array}{l}\text { Degraded blades of the low-pressure } \\
\text { turbine (DLB) }\end{array}$ & Repair \\
\hline $10^{14}<D \leq 2.2 \times 10^{14}$ & Degraded basic material of disks (DD) & Repair \\
\hline$D>2.2 \times 10^{14}$ & Melted blades (MB) & Out of operation \\
\hline
\end{tabular}

Table 2. Assessment of performance capability of the aircraft engine in terms of the parameter D. Copyright 2010 by Elsevier B.V., Engineering Failure Analysis (in print), reproduced with permission

Polycrystalline rotor blades are made of nickel-based superalloy by a precise casting. They are designated for work temperatures in the range of $800-1050{ }^{\circ} \mathrm{C}$. In the engine DV2 the blades of the high-pressure turbine are protected from high-temperature waste gases by using the heat-resistant AS layer. The procedure consists in the spraying of an equally balanced suspension of aluminum and silicon powders together with the coloxylin as a binder. Diffusive tempering is applied at $1000{ }^{\circ} \mathrm{C}$ in an inert argon atmosphere with the dwell time of 3 hours and subsequent slow cooling in the retort. The final microstructure of the layer consists of two sublayers. The outer one is composed of mostly alloyed aluminides and a small amount of carbides, the inner one contains aluminides of a lower Al-content and finely dispersed carbides and silicides, see also Fig. 15.

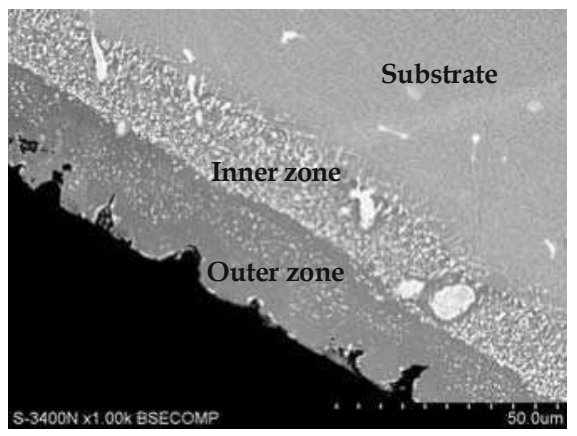

Fig. 15. The protective coatings just after deposition.

The degradation of the AS layer was analyzed for blades that were subjected to different overheating conditions during service (Pokluda et al., 2008, Kianicová et al., 2009). It was found that the relative thickness of the degraded surface layer was a monotonically decreasing function of the parameter $D$ (Kianicová \& Pokluda, 2007). This is demonstrated in Fig. 16. (Pokluda \& Kianicova, 2010), where the relative thickness $h_{r}=h / h_{0}$ of the diffusive 
protective layer on the back (convex side) and the trough (concave side) of the blade is plotted as a function of $\log D$. The points indicate the results of measurements performed on blades coming from four engines that experienced overheating of various intensities (see Pokluda et al., 2008 for more detail).

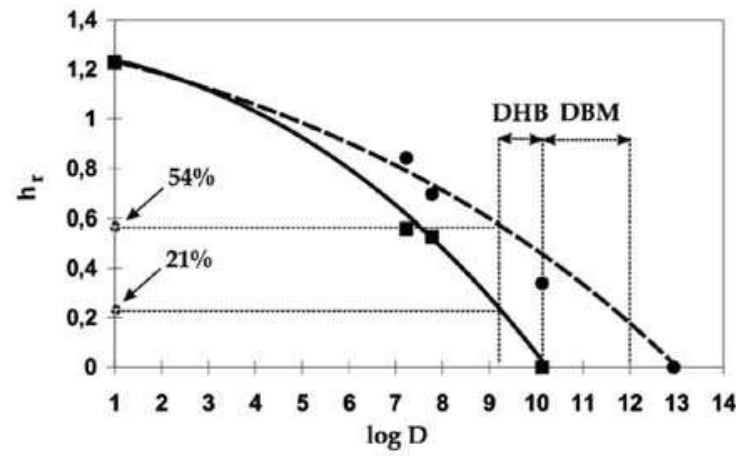

Fig. 16. Dependence of the relative thickness $h_{\mathrm{r}}$ of the coating on the level of degradation in terms of the parameter $D$ for $n=3 ; p=1 / 4$ and $q=3 / 4$ (Pokluda \& Kianicova, 2010). The solid curve stands for through whereas the dashed one for the back of the blade. Copyright 2010 by Elsevier B.V., Engineering Failure Analysis (in print), reproduced with permission

The value $h_{0} \approx 28 \mu \mathrm{m}$ corresponds to the average initial thickness of the virgin layer. Both curves start at $h_{\mathrm{r}}=h_{\max } / h_{0}=1.23(\log D=1)$ which is related to the maximum average thickness $h_{\max } \approx 34 \mu \mathrm{m}$ of the diffusive coating. Such a thickness is achieved after several hours of service under a standard working temperature (Kianicová, 2006).

One can see that the following quadratic relationships

$$
\begin{aligned}
& h_{r b}=1.2734-0.0295 \log D-0.0055(\log D)^{2} \\
& h_{r t}=1.2540-0.0141 \log D-0.0108(\log D)^{2}
\end{aligned}
$$

well approximate the reduction of the relative thickness on both the back $\left(h_{\mathrm{rb}}\right)$ and the through $\left(h_{\mathrm{rt}}\right)$ after the overheating events of various intensities. The damage curve for the back lies above that for the through. This means that the latter curve is crucial for the assessment of the damage level of the blade according to the benchmarks DHB and DBM given in Table 1 . The value $h_{\mathrm{rt}}=0.21$ related to the benchmark $D_{D H B}=1.5 \cdot 10^{9}{ }^{\circ} \mathrm{C}^{4} \mathrm{~s}^{2}$ that indicates an onset of the range of the necessary repair seems to be very reasonable: $79 \%$ of the original through layer and $46 \%$ of the original back layer is already removed. Moreover, the trough layer is totally removed when reaching the value $h_{\mathrm{rt}}=0$ which exactly corresponds to the benchmark $D_{D B M}=1010{ }^{\circ} \mathrm{C}^{4} \mathrm{~S}^{2}$ indicating a start of the degradation of the basic material. Thus, the description of blade damage using the parameter $D$ according to eq. (22) seems to be very plausible.

The parameter $D$ possesses an interesting physical meaning. When assuming a creep work done by tensile misfit stresses during the overheating event (Fig. 14), one can show that this parameter is directly proportional to the specific Hamiltonian's action $S_{\mathrm{E}}$ that contains a basic information about the evolution of damage in the system (Pokluda \& Kianicova, 2010). 
Consequently, the damage function can be expressed in more general form as

$$
S_{E} \propto D=\left(t_{2}-t_{0}\right)^{1+q-n p}\left[T_{\max }-T_{c}\right]^{q(n+1)}\left\{\int_{t_{0}}^{t_{2}}\left[T(t)-T_{c}\right] d t\right\}^{p(n+1)},
$$

where $p+q=1$ and $n \in(1,6)$. The parameter $D$ defined by eq. (22) represents a special case of eq. (24) for $p=1 / 4, q=3 / 4$ and $n=3$. Note that the value $n=3$ indicates a plausible mixture of diffusion and dislocation damage mechanisms during the creep exposure.

On the other hand, one cannot exclude the possibilty of other suitable forms of the damage parameter since various sets of parameters $n, p$ and $q$ (different from $n=3, p=1 / 4$ and $q=$ $3 / 4)$ can basically be considered as well. When retaining the physical meaning of $D$ in terms of the unit $\left({ }^{\circ} \mathrm{C}^{\mathrm{n}+1} \mathrm{~s}^{2}\right)$ and avoiding both fractions and negative values of powers in eq. (24), one can find 28 various possible combinations of these parameters. However, the related numerical analysis revealed that the parameter $D$ as defined by eq. (22) can, indeed, be considered to be the best of all these alternative damage indicators (Pokluda \& Kianicova, 2010). Nevertheless, a much simpler damage parameter

$$
D_{n}=\left(t_{2}-t_{0}\right)^{2}\left[T_{\max }-T_{c}\right]^{4},
$$

as a nearly equivalent to $D$ could be found in this way. To justify a reliability of the parameter $D_{n}$ would, however, need a further verification.

The assessment procedure based on the parameter $D$ does not provide correct data in the following special cases (Kianicová et al., 2009):

i. The overheating is caused by a gas burning outside the combustion chamber which results in a sudden decrease of turbine revolutions;

ii. Repeated overheating of the engine.

However, these cases can be easily identified when analyzing records of the turbine revolutions and the overheating events during service (Pokluda et al., 2008).

\section{Conclusion}

Protective coatings on blades serve as physical barriers between the underlying substrate and the outer environment. This article presents an overview of damage mechanisms leading to failure of all basic types of coatings (diffusion, overlay and thermal barrier) on turbine blades of aircraft engines during service. Although a special emphasize is devoted to destructive effects of thermo-mechanical fatigue and overheating, the severe effects of hot corrosion, oxidation and erosion effects are also described. Most important material and design parameters of coatings are highlighted with respect to an optimum protection from damage caused by aggressive environment and thermo-mechanical loading. For this purpose, many recent results of advanced numerical models based on fracture mechanics are taken into account. A simple method for an assessment of performance capability of diffusive coatings is presented as a case study performed on rotor blades of high-pressure turbines in aircraft engines. Thus, this article provides scientists, researchers and designers with not only a deep insight into basic degradation micromechanisms of protective coatings, but also a practical example of engineering application. 


\section{Acknowledgement}

This work was supported by the Ministry of Industry and Trade of the Czech Republic in the frame of the Project FR-TI1/237 099.

\section{References}

Borom, M.P., Johnson, C.A., Peluso, L.A. (1996) Role of environment deposits and operating surface temperature in spallation of air plasma sprayed thermal barrier coatings. Surface and Rating Technology. Vol. 86-87, No 1, (December 1996) pp. 116-126, ISSN 0257-8972.

Bose, S. (2007) High temperature Coatings. Elsevier Science \& Technology Books, ISBN 0750682523.

Ciesla, M., Swadzba, L. (2006). Cracking processes during creep test of JS6U superalloy with aluminum coatings. Journal of Achievements in Materials and Manufacturing Engineering. Vol. 17, No. 1-2, ( 2006) pp. 177-180. ISSN 17348412.

Committee on Coatings for High-temperature Structural Materials (1996). Coatings for Hightemperature Structural Materials; Trends and Opportunities. National Academy Press, ISBN 978-0-309-08683-7. Washington.

Crowell, M.W., Wang, J., McMeeking, R.M., Evans, A.G. (2008) Dynamics of kink band formation in columnar thermal barrier oxides. Acta Materialia. Vol. 56, No. 16, (September 2008) pp. 4150-4159. ISSN 1359-6454.

Donachie, M.J., Donachie, S.J. (2002) Superalloys: A technical guide, Second Edition. ASM International, ISBN 0-87170-749-7. Materials Park, OH.

Eliaz, N., Shemes, G., Latanision, R.M. (2002. Hot corrosio in gas turbine components. Engineering Failure Analysis, Vol.9, No.1 (February 2002), pp. 31-43, ISSN 1350-6307.

Eskner, M. (2004) Mechanical Behaviour of Gas Turbine Coatings. Doctoral Thesis. Stockholm: Department of Materials Science and Engineering Royal Institute of Technology, 61 pp. ISBN 91-7283-786-1.

Evans, A.G., Hutchinson, J.W., Wei, Y. (1999) Interface adhesion: Effects of plasticity and segregation. Acta Materialia.Vol. 47, No. 15-16, (November 1999), pp. 4903-4113. ISSN 1359-6454.

Evans, A.G., Mumm, D.R., Hutchinson, J.W., Meier, G.H., Pettit, F.S. (2001a) Mechanism controlling the durability of thermal barrier coatings. Progress in Materials Science. Vol. 46, No. 5, (2001) pp. 505-553. ISSN 0079-6425.

Evans, A.G., Hy, M.Y., Hutchinson, J.W. (2001b) Mechanics-based scaling laws for the durability of thermal barrier coatings. Progress in Materials Science. Vol. 46, No. 3-4, (2001) pp. 249-271. ISSN 0079-6425.

Evans, A.G., He, M.Y., Hutchinson, J.W. (2003). Effects of interface undulation on the thermal fatigue of thin films and scales on metal substrates. Acta Materialia. Vol. 51, No. 7, (September 1997) pp. 2017-2030. ISSN 1359-6454.

Evans, G.E., Clarke, D.R., Levi, C.G. (2008). The influence of oxides on the performance of advanced gas turbines. Journal of the European Ceramic Society. Vol. 28, No. 7, (2008), pp. 1405-1419. ISSN 0955-2219.

He, M.Y., Evans, A.G., Hutchinson, J.W.(1998). Effects of morfology on the decohesion of compressed thin films. Materials Science and Engineering A. Vol. 245, No 2, (May 1998), pp. 168-181. ISSN 0921-5093. 
He, M.Y., Evans, A.G., Hutchinson, J.W. (2000). The ratcheting of compressesd thermally grown thin films on ductile substrate. Acta Materialia. Vol. 48, No. 10, (June 2000), pp. 2593-2601. ISSN 1359-6454.

HTC-AED a.s. Povazska Bystrica, (1998). The manual of the turbine-design department, (1998), Slovakia.

Huang, Z.W., Wang, Z.G., Zhu, S.J., Juan, F.H., Wang, F.G. (2006). Thermomechanical fatigue behavior and life prediction of a cast nickel-based superalloy. Materials Science and Engineering A. Vol. 432, No. 1-2, (September 2006) pp. 308-316. ISSN 0921-5093.

Hutchinson, J.W., Suo, Z. (1992). Mixed mode cracking in layered materials. Advances in Applied Machanics. (1992). Vol. 29, pp. 63-191. ISBN 0-12-002029-7.

Chen, X., Wang, R., Yao, N., Evans, A.G., Hutchinson, J.W., Bruce, R.W. (2003). Foreign object damage in a thermal barrier system: mechanisms and simulations. Materials Science and Engineering A. Vol. 352, No 1-2, (July 2003), pp. 221-231. ISSN 0921-5093.

Chen, X., He, M.Y., Spitsberg, I., Fleck, N.A., Hutchinson, J.W., Evans, A.G. (2004). Mechanisms governing the high temperature erosion of thermal barrier coatings. Wear. Vol. 256, No. 7-8, (April 2004) pp. 735-746. ISSN 0043-1648.

Kianicová, M., Pokluda, J. (2007) Degradation of protective Al-Si coatings during exploitation of gas turbine blades. Materials Science Forum, Vol. 567-568 (December 2007) pp. 309-312. ISSN: 1662-9752.

Kianicová, M., Pospíšilová, S., Zahoran, M. (2009). Damage of protective Coating due to unstable Engine Running, Proceedings of 12th International Conference on Fracture. Ottawa, July 2009, National Research Council Canada.

Kianicová M., (2006). Fireproof diffusive coating degradation in consequence of short-time operating temperature exceeding, PhD Thesis, AD University in Trencin, 2006.

Krämer, S., Fauhaber, S., Chambers, M., Clarke, D.R., Levi, C.G., Hutchinson, J.W., Evans, A.G. (2008). Mechanisms of cracking and delamination within thick thermal barrier systems in aero-engines subject to calcium-magnesium-alumino-silicate (CMAS) penetration. Materials Science and Engineering A. Vol. 490, No 1-2, 25 (August 2008) pp. 26-35. ISSN 0921-5093.

Mercer, C., Faulhaber, S., Evans, A.G., Darolia, R. (2005). A delamination mechanism for thermal barrier coatings subject to calcium-magnesium-alumino-silicate (CMAS) infiltration. Acta Materialia. Vol. 53, No. 4, (February 2005), pp. 1029-1039. ISSN 1359-6454.

NASA, (2003), Report: NASA/TM-2003-212030.

Nicholls, J.R., Jaslier, Y., RIickerby, D.S. (1998). Erosion of EB-PVD thermal barrier coatings. Materials at High Temperatures. Vol. 15, No. 1, (February 1998) pp. 15-22. ISSN 09603409.

Nicholls, J.R. (2000). Designing Oxidation-Resistant Coatings. JOM. Vol. 52, No. 1. (January 2000) pp. 28-35. ISSN 1543-1851.

Pokluda, J., Kianicová, M., Švejcar, J. (2008). Degradation of protective coatings of turbine blades during exploitation. Proceedings of Failures 2008, pp. 139-159, South Africa, March 2008, Strand.

Pokluda, J., Kianicová, M. (2010). Assessment of performance capability of turbine blades with protective coatings after overheating events. Engineering Failure Analysis. doi:10.1016/j.engfailanal.2010.04.004. 
Rabiei, A. Evans, A.G. (2000). Failure mechanisms associated with the thermally grown oxide in plasma-sprayed thermal barrier coatings. Acta Materialia., Vol. 48, No. 15, (September 2000), pp. 3963-3976. ISSN 1359-6454.

Rangaraj, S., Kokini, K. (2003), Fracture in single-layer zirconia (YSZ)-bond coat alloy (NiCoCrAlY) composite coatings under thermal shock. Acta Materialia. Vol. 52, No. 1, (January 2003), pp. 455-465. ISSN 1359-6454.

Rapp, R.A. (2001). Encyclopedia of Materials - Science and Technology. Surface Coating for High-temperature Alloys. Elsevier, ISBN 978-0-08-052358-3. Amsterdam.

Strangman, T., Raybould, D., Jameel, A., Baker, W. (2007). Damage mechanisms, life prediction, development of EB-PVD thermal barrier coatings for turbine airfoils. Surface and Coating Technology. Vol. 202, No. 4-7, (December 2007), pp. 658-664. ISSN 0257-8972.

Suo, Z. (1993). Cracking and debonding of microlaminates. Journal of Vacuum Science and Technology A. Vol. 11, no. 4, pp. 1367-1372. ISSN 0734-2101.

Tamarin, Y. (2002). Protective Coatings for Turbine Blades. ASM International, ISBN 0-87170759-4, Ohio.

Tawancy, H.M., Al-Hadrami, L. (2008). Applications of microstructural characterization and computational modeling in damage analysis of a turbine blade exposed to service conditions in a power plant. Engineering Failure Analysis. Vol. 15, No. 8, (December 2008), pp. 1027-1034. ISSN 1350-6307.

Tawancy, H.M., Al-Hadrami, L. (2009). Degradation of turbine blades and vanes by overheating in a power station. Engineering Failure Analysis. Vol. 16, No. 1, (January 2009), pp. 273-280. ISSN 1350-6307.

Tolpygo, V.K., Clarke, D.R. (1998). Wrinkling of a-alumina films grown by oxidation - II. Oxide separation and failure. Acta Materialia. Vol. 46, No. 14, (September 1998), pp. 5167-5174. ISSN 1359-6454.

Tolpygo, V.K., Clarke, D.R. (2000). Surface rumpling of a (Ni, Pt) Al bond coat induced by a cyclic oxidation. Acta Materialia. Vol. 48, No. 13, (August, 2000), pp. 3283-3293. ISSN 1359-6454.

Tolpygo, V.K., Clarke, D.R., Murphy, K.S. (2004). Evaluation of interface degradation during cyclic oxidation of EB-PVD thermal barrier coatings and correlation with TGO luminiscence. Surface and Coating Technology. Vol. 188-189, (November - December 2004) pp. 62-70. ISSN 0257-8972.

Wang, J.S., Evans, A.G. (1998). Measurement and analysis of buckling and buckle propagation in compressed oxide layers on superalloy substrates. Acta Materialia. Vol. 46, No. 14, (september 1998), pp. 4993-5005. ISSN 1359-6454.

Wang, J.S., Evans, A.G. (1999). Effects of strain cycling on buckling, cracking and spalling of a thermally grown alumina on a nickel-based bond coat. Acta Materialia. Vol. 47, No. 2, (January 1999), pp. 699-710. ISSN 1359-6454.

Wang, Q.M., Tang, J., Guo, M.H., Ke, P.L., Gong, J., Sun, C., Wen, L.S. (2005) Thermal shock cycling behavior of NiCoCrAlYSiB coatings on Ni-base superalloys II. Microstructure evolution. Materials Science and Engineering A. Vol. 406, No. 1-2, (October 2005), pp. 350-357.

Wellman, R.G., Deakin, M.J, Nicholls, J.R. (2005). The effect of TBC morphology and aging on the erosion rate of EB-PVD TBCs. Tribology International. Vol. 38, No. 9, (September 2005), pp. 798-804. ISSN 0301-679X. 


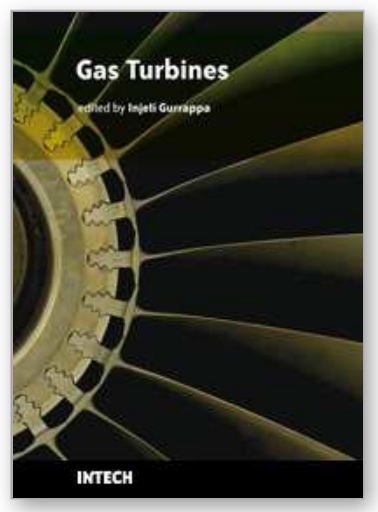

\author{
Gas Turbines \\ Edited by Gurrappa Injeti
}

ISBN 978-953-307-146-6

Hard cover, 364 pages

Publisher Sciyo

Published online 27, September, 2010

Published in print edition September, 2010

This book is intended to provide valuable information for the analysis and design of various gas turbine engines for different applications. The target audience for this book is design, maintenance, materials, aerospace and mechanical engineers. The design and maintenance engineers in the gas turbine and aircraft industry will benefit immensely from the integration and system discussions in the book. The chapters are of high relevance and interest to manufacturers, researchers and academicians as well.

\title{
How to reference
}

In order to correctly reference this scholarly work, feel free to copy and paste the following:

Jaroslav Pokluda and Marta Kianicová (2010). Damage and Performance Assessment of Protective Coatings on Turbine Blades, Gas Turbines, Gurrappa Injeti (Ed.), ISBN: 978-953-307-146-6, InTech, Available from: http://www.intechopen.com/books/gas-turbines/damage-and-performance-assessment-of-protective-coatingson-turbine-blades

\section{INTECH}

open science | open minds

\section{InTech Europe}

University Campus STeP Ri

Slavka Krautzeka 83/A

51000 Rijeka, Croatia

Phone: +385 (51) 770447

Fax: +385 (51) 686166

www.intechopen.com

\section{InTech China}

Unit 405, Office Block, Hotel Equatorial Shanghai

No.65, Yan An Road (West), Shanghai, 200040, China 中国上海市延安西路65号上海国际贵都大饭店办公楼 405 单元

Phone: +86-21-62489820

Fax: $+86-21-62489821$ 
(C) 2010 The Author(s). Licensee IntechOpen. This chapter is distributed under the terms of the Creative Commons Attribution-NonCommercialShareAlike-3.0 License, which permits use, distribution and reproduction for non-commercial purposes, provided the original is properly cited and derivative works building on this content are distributed under the same license. 